\title{
PENGARUH STRATEGI PEMBELAJARAN EVERYONE IS A TEACHER HERE TERHADAP HASIL BELAJAR AKUNTANSI SISWA KELAS XI SMK PAB 2 HELVETIA TAHUN PELAJARAN 2019/2020
}

\author{
Ramayani \\ Dian Novianti Sitompul \\ Program Studi Pendidikan Akuntansi \\ Fakultas Keguruan dan Ilmu Pendidikan \\ Universitas Muhammadiyah Sumatera Utara \\ Email : diannovianti@umsu.ac.id
}

\begin{abstract}
ABSTRAK
Penelitian ini bertujuan untuk mengetahui apakah terdapat pengaruh strategi pembelajaran setiap orang guru disini terhadap hasil belajar akuntansi siswa kelas XI AK SMK PAB 2 Helvetia tahun pelajaran 2019/2020. Sampel dalam penelitian ini adalah siswa kelas XI-Ak yang berjumlah 35 siswa. Teknik yang digunakan dalam pengambilan sampel adalah total sampling. Instrumen yang digunakan adalah angket dan tes. Angket terdiri dari 20 soal dan tes terdiri dari 20 soal, 10 soal pre-tes dan 10 soal post-tes, tes yang digunakan dalam bentuk uraian. Penelitian ini dilakukan di Sekolah Menengah Kejuruan (SMK) PAB 2 Helevetia yang beralamat di Jalan Veteran Pasar IV Helvetia, Labuhan Deli, Tj.Gusta, Deli Serdang, Sumatera Utara, 20116. Permasalahan dalam penelitian ini adalah rendahnya hasil belajar siswa kelas XI AK akuntansi SMK PAB 2 Helvetia. Berdasarkan persamaan regresi linier sederhana, $Y=64,177+0,265$ $X$. Dari persamaan regresi linier sederhana diperoleh nilai a (bilangan tunai) dari Unstandardized Coefficient adalah 64,177. Artinya apabila tidak ada strategi semua orang menjadi guru disini (X) maka nilai hasil belajar (Y) adalah 64,177. Sedangkan b (jumlah koefisien regresi) bernilai 0,265 , hal ini menunjukkan bahwa setiap penambahan $1 \%$ level strategi pembelajaran setiap orang menjadi guru disini $(X)$ maka hasil belajar $(Y)$ akan meningkat sebesar 0,265. Karena nilai koefisien regresi bertanda positif maka dapat dikatakan bahwa strategi semua orang mengajar disini $(X)$ berpengaruh positif terhadap hasil belajar (Y). Dari hasil pengujian hipotesis pada taraf signifikan 5\% atau 0,05 diperoleh thitung > ttabel yaitu 3,851>1,692 maka dapat disimpulkan bahwa Ha diterima. Hasil ini menunjukkan bahwa terdapat pengaruh strategi pembelajaran setiap orang sebagai guru di sini terhadap hasil belajar akuntansi siswa kelas XI SMK PAB 2 Helvetia tahun pelajaran 2019/2020.
\end{abstract}

Kata Kunci : Strategi Pembelajaran, everyone is a teacher here, hasil belajar

\section{Abstract}


This study aims to determine whether there is an influence on the learning strategy of everyone is a teacher here on the accounting learning outcomes of students of class XI AK SMK PAB 2 Helvetia in the academic year 2019/2020.The sample in this study was class XI-Ak, amounting to 35 students. The technique used in sampling is total sampling. The instruments used were questionnaires and tests. The questionnaire consisted of 20 items and the test consisted of 20 questions, 10 pre -test questions and 10 post-test questions, the test used in the form of a description. This research was conducted at the PAB 2 Helevetia Vocational High School (SMK) which is located at Jalan Veteran Pasar IV Helvetia, Labuhan Deli, Tj.Gusta, Deli Serdang, North Sumatra, 20116. The problem in this study is the low learning outcomes of the XI AK SMK grade accounting PAB 2 Helvetia. Based on the simple linear regression equation, $\mathrm{Y}=64,177+0,265 \mathrm{X}$. From the simple linear regression equation the value that the value of a (cash number) from Unstandardized Coefficient is 64,177. This means that if there is no strategy everyone is a teacher here $(\mathrm{X})$ then the value of learning outcomes (Y) is 64,177 . While $b$ (the number of regression coefficients) the value of 0.265 , this shows that each additional $1 \%$ level of learning strategies everyone is a teachere here $(\mathrm{X})$ then the learning outcomes $(\mathrm{Y})$ will increase by 0.265 . Because the value of the regression coefficient is positive, it can be said that the strategy of everyone is a teachere here $(\mathrm{X})$ has a positive effect on learning outcomes (Y). From the results of hypothesis testing, at a significant level of $5 \%$ or 0.05 obtained tcount $>$ ttable is 3.851>1.692, it can be concluded that $\mathrm{Ha}$ is accepted. These results indicate that there is an effect of the learning strategy everyone is a teachere here to the learning outcomes of accounting class XI SMK PAB 2 Helvetia in the academic year 2019/2020.

Keywords : Learning Strategy Everyone is a Teacher Here, Learning Outcomes

\section{PENDAHULUAN}

Pada era globalisasi pendidikan memegang peran penting karena pendidikan merupakan wadah untuk meningkatkan dan mengembangkan kualitas sumber daya manusia. Salah satu cara yang dilakukan untuk meningkatkan mutu dan kualitas pendidikan adalah dengan cara pembaharuan sistem pendidikan. Pendidikan yang dimaksud disini adalah siswa yang dituntut aktif dalam pembelajaran atau pembelajaran berpusat pada siswa (student centre) dan sebaliknya bukan guru yang 
Volume 3. No.2 Agustus 2020 (96-107)

Doi 10.30596/liabilities.v3i2.5592

memberikan pengetahuan kepada siswa (teacher centre) atau sumber satusatunya untuk belajar karena guru hanya sebagai fasilitator dan motivator untuk mencapai tujuan pendidikan. Berhasil atau tidaknya suatu pendidikan sangat dipengaruhi oleh pembelajaran yang berlangsung. Pembelajaran merupakan suatu proses yang rumit karena bukan hanya sekedar menyerap informasi dari guru tetapi melibatkan berbagai kegiatan dan tindakan yang harus dilakukan untuk meningkatkan hasil belajar yang lebih baik. dilihat dari hasil ujian tengah semester yang diperoleh siswa dengan jumlah siswa 35 orang, hanya 10 orang yang memiliki nilai tuntas dan 25 orang yang dinyatakan tidak tuntas, padahal nilai Kriteria Ketuntasan Minimal (KKM) yang ditentukan sekolah tersebut untuk mata pelajaran akuntansi adalah 75 . Tabel dibawah ini menunjukkan hasil belajar siswa sebagai berikut:

Tabel 1. Hasil belajar Siswa Kelas $X$ AK 1 SMK PAB 2 Helvetia

\begin{tabular}{|c|c|c|c|}
\hline No & $\begin{array}{c}\text { Jumlah } \\
\text { Siswa }\end{array}$ & Nilai & Persentase \\
\hline $\mathbf{1}$ & 10 & $\geq 75$ & $28,57 \%$ \\
\hline
\end{tabular}

\begin{tabular}{|c|c|c|c|}
\hline $\mathbf{2}$ & 25 & $<75$ & $71,43 \%$ \\
\hline Jumlah & $\mathbf{3 5}$ & & $\mathbf{1 0 0 \%}$ \\
\hline
\end{tabular}

Sumber: Daftar Nilai Ujian Mid Semester Kelas X AK PAB Helvetia

Dari tabel diatas dapat dilihat bahwa masih banyak siswa yang hasil belajar akuntansinya masih dibawah KKM yang ditetapkan sekolah. Hal ini menunjukkan bahwa hasil belajar akuntansi masih perlu ditingkatkan. Rendahnya hasil belajar siswa dapat berasal dari siswa yang kurang aktif dalam proses pembelajaran, siswa hanya mendengarkan dan mencatat penjelasan dari guru, siswa malu dalam bertanya dan tidak berani mengungkapkan pendapatnya, kurang efektifnya metode dan strategi pembelajaran yang digunakan guru, Dimana peranan guru sangat dominan dan tidak memberikan akses bagi siswa untuk berkembang secara mandiri sehingga siswa menjadi bosan.

Guru sebagai individu yang memiliki andilyang cukup besar mengusahakan segala cara agar siswa dituntut berani maju kedepan kelas dan memaparkan materi kepada teman-temannya yang belum engerti atau belum paham tentang materi yang dipelajari (siswa seakan-akan menjadi guru untuk 
temannya), dengan demikian maka perlu diterapkan strategi yang kreatif dan inovatif yang menuntut siswa untuk berani berbicara dan menjelaskan didepan kelas. Untuk mengatasi masalah diatas, banyak model dan strategi pembelajaran yang dapat digunakan untuk meningkatkan hasil belajar siswa. Salah satu yang dapat digunakan adalah dengan menggunakan strategi pembelajaran Everyone is a Teacher Here. Strategi pembelajaran ini merupakan strategi yang berpusat pada siswa, artinya pembelajaran ini lebih banyak melibatkan aktivitas siswa dalam mengakses berbagai informasi dan pengetahuan untuk dibahas dan dikaji dalam pembelajaran dikelas.Sehingga mereka mendapatkan berbagai pengalaman yang dapat meningkatkan pemahaman dan kompetensinya. Menurut Zaini, dkk (2011:60) "Strategi pembelajaran Everyone Is a Teacher Here adalah Salah satu teknik instruksional dari belajar aktif (active learning) yang termasuk dalam peer teaching (pembelajaran rekan sebaya). Tipe ini memberikan kesempatan untuk bertindak sebagai guru bagi siswa lainnya. Strategi ini merupakan cara yang mudah untuk mendapatkan partisipasi dari seluruh kelas". Strategi pembelajaran Everyone is a Teacher Here merupakan strategi pembelajaran aktif yang mudah untuk memperoleh partisipasi siswa dan kelas yang besar dan tanggung jawab individu. Strategi ini memberi kesempatan kepada peserta didik untuk bertindak sebagai seorang "pengajar" terhadap peserta didik lain. Pembelajaran everyone is a Teacher Here lebih mengutamakan peranan siswa, sehingga dalam pelaksanaannya siswa sendiri yang akan memberikan penjelasan kepada kawan kawannya yang belum mengerti atau belum paham materi yang dipelajari. Ini disebabkan, strategi Everyone is a Teacher Here bertujuan membiasakan peserta didik untuk belajar secara individu mendengarkan dengan aktif, menjelaskan kepada temannya, bertanya pada guru. MenurutWarsono (2017:46) langkah-langkah dalam strategi pembelajaran Everyone Is a Teacher Here, sebagai berikut :

a) Bagikan kartu indeks kepada setiap siswa dalam kelas.

b) Mintalah kepada para siswa untuk menuliskan sebuah pertanyaan yang paling akhir dipelajari dari bidang studi yang 
baru saja anda ajarkan (maksudnya bisa saja bahan ajar yang baru saja dibicarakan atau baru saja didiskusikan pada kesempatan pertemuan yang lalu). Cukup satu pertanyaan saja, yang penting esensi relevan, dan tulisannya dapat dibaca oleh siswa lain.

c) Kumpulkan kartu indeks, lalu acaklah kartu-kartu indeks tersebut sedemikian rupa sebelum dibagikan kembali kepada setiap siswa, sehingga tidak ada satu pembelajar pun yang menerima soal yang dibuatnya sendiri.

d) Kemudian setiap siswa diminta untuk membaca dan mencoba memikirkan jawaban dari pertanyaan yang diajukan dalam kartu indeks.

e) Mintalah para siswa secara sukarela, atau anda dapat menunjuk secara acak seorang siswa untuk membaca dengan suara keras pertanyaan tersebut dan mencoba menjawabnya.

f) Setelah jawaban diberikan, mintalah siswa yang lain untuk menanggapinya.

g) Lanjutkan dengan sukarelawan berikutnya sampai waktu yang disediakan habis. Jika tidak cukup waktunya, sisa pertanyaan yang belum dijawab dan diterangkan secara ringkas oleh guru pada sesi pembelajaran berikutnya.

\section{METODE PENELITIAN}

Jenis penelitian yang digunakan adalah eksperimental yang pelaksanaannya melibatkan atau menggunakan satu kelas. menurut Sugiono (2012:107) menyatakan bahwa "Metode Penelitian eksperimental adalah metode peneliti yang digunakan untuk mencari pengaruh perlakuan tertentu terhadap yang lain dalam kondisi yang terkendalikan”. Populasi dari peneliti ini adalah seluruh kelas XI AK SMK PAB 2 Helvetia yang terdiri dari 1 kelas yang berjumlah 35 orang. Peneliti melakukan pengambilan sampel dengan menggunakan Total Sampling sehingga sampel penelitian ini yaitu kelas XI Akuntansi yang berjumlah 35 siswa. Instrument yang digunakan dalam penelitian ini adalah angket dan tes. Teknik analisis data yang digunakan dalam penelitian ini adalah uji kuantitas data, uji prasyarat (uji normalitas dan uji reliabilitas), uji regresi linier sederhana,uji korelasi,uji koefisien determinan dan uji t.

\section{PEMBAHASAN DAN HASIL PENELITIAN}

Penelitian dilakukan di kelas XI- AK SMK PAB 2 Helvetia, yang melibatkan 1 kelas yaitu XI AK-1. Data yang diambil ada 2 jenis yaitu penggunaan strategi pembelajaran Everyone is a teacher here (X) dan hasil belajar akuntansi (Y). 
Volume 3. No.2 Agustus 2020 (96-107)

Doi 10.30596/liabilities.v3i2.5592

Pengumpulan data dilakukan dengan cara memberikan pre terst, post test dan angket. Setelah penelitian dilakukan, maka diperoleh skor hasil belajar siswa berupa pre test, post test pada materi mengelolah dana kas kecil serta hasil angket mengenai strategi pembelajaran everyone is a teacher here. Nilai pre test dan post test terlampir.

Tabel 2 Data Skor Hasil Belajar

\begin{tabular}{|c|c|c|c|c|c|c|}
\hline \multirow{5}{*}{\multicolumn{3}{|c|}{$\begin{array}{l}\text { strategi pembelajaran everyone is a } \\
\text { teacher here. Nilai pre test dan post } \\
\text { test terlampir. } \\
\text { Tabel } 2 \text { Data Skor Hasil Belajar }\end{array}$}} & \multirow{2}{*}{\begin{tabular}{|c|}
$\begin{array}{c}\text { Nomor } \\
\text { Soal }\end{array}$ \\
1
\end{tabular}} & \multirow{2}{*}{$\frac{}{0,862}$} & \multirow{2}{*}{0,312} & \multirow{2}{*}{$\begin{array}{c}\text { Keterangan } \\
\text { Valid } \\
\end{array}$} \\
\hline & & & & & & \\
\hline & & & 2 & 0,851 & 0,312 & Valid \\
\hline & & & 3 & 0,922 & 0,312 & Valid \\
\hline & & & 4 & 0,761 & 0,312 & Valid \\
\hline & \multirow{2}{*}{ Post_Test } & \multirow{2}{*}{ Pre_Test } & 5 & 0,891 & 0,312 & Valid \\
\hline & & & 6 & 0,863 & 0,312 & Valid \\
\hline Valid & \multirow[t]{3}{*}{35} & \multirow[b]{4}{*}{42,1} & 7 & 0,848 & 0,312 & Valid \\
\hline Missing & & & 8 & 0,904 & 0,312 & Valid \\
\hline & & & 9 & 0,830 & 0,312 & Valid \\
\hline Mean & 79,14 & & 10 & 0,713 & 0,312 & Valid \\
\hline Median & 80,00 & 40,0 & 11 & 0,832 & 0,312 & Valid \\
\hline \multirow[t]{2}{*}{ Std. Deviation } & \multirow[t]{2}{*}{11,662} & \multirow[t]{2}{*}{23,013} & 12 & 0,637 & 0,312 & Valid \\
\hline & & & 13 & 0,741 & 0,312 & Valid \\
\hline Variance & 136,008 & $529,83=$ & 14 & 0,863 & 0,312 & Valid \\
\hline nimum & \multirow[t]{2}{*}{55} & 1. & 15 & 0,743 & 0,312 & Valid \\
\hline \multirow{2}{*}{ Maximum } & & & 16 & 0,798 & 0,312 & Valid \\
\hline & 100 & & 17 & 0,554 & 0,312 & Valid \\
\hline \multirow{3}{*}{ Berdasarkan } & \multirow{3}{*}{\multicolumn{2}{|c|}{ diatas, terlihat }} & 18 & 0,650 & 0,312 & Valid \\
\hline & & & 19 & 0,460 & 0,312 & Valid \\
\hline & & & 20 & 0,303 & 0,312 & Valid \\
\hline
\end{tabular}

bahwa rata-rata skor hasil belajar siswa saat post test lebih tinggi dibanding saat pre test dengan selisih skor sebesar 37,00. Skor hasil belajar saat post test juga memiliki rentang skor yang lebih panjang dibanding saat pre test, dengan skor minimum lebih tinggi post test daripada pretest serta lebih tinggi skor maximum di post test dari pada pre test yaitu dengan selisih 15.

1. Uji Kuantitas Data

a. Uji validitas

Tabel 3 Uji validitas Angket

Variabel X

Sumber : Data diolah menggunakan SPSS 23

Tabel diatas mengidentifikasi bahwa semua angket dikatakan valid

b. Uji Reliabilitas

Tabel 4 Hasil Perhitungan Uji 
Volume 3. No.2 Agustus 2020 (96-107)

Doi 10.30596/liabilities.v3i2.5592

Reliabilitas Angket

Reliability Statistics

\begin{tabular}{|r|r|}
\hline $\begin{array}{c}\text { Cronbach's } \\
\text { Alpha }\end{array}$ & N of Items \\
\hline, 958 & 20 \\
\hline
\end{tabular}

Berdasarkan kriteria suatu instrument penelitian dikatakan data tersebut reliabel jika nilai Cronbach's Alpha > 0,60. Berdasarkan nilai Alpha pada kolom Cronbach's Alpha diatas, terlihat bahwa nilai Cronbach's Alpha $>0,60$ yaitu 0,958 0,60 hal ini menunjukkan bahwa data tersebut reliabel.

\section{Uji Asumsi Klasik}

a. Uji Normalitas

Uji normalitas data digunakan untuk mengetahui normal tidaknya suatu distribusi data. Untuk pengujian normalitas data menggunakan uji Kolmogorov-Smirnov.

Tabel 5. Hasil Uji Normalitas One-Sample Kolmogorov-Smimov Test

\begin{tabular}{|l|l|}
\hline & \\
\hline $\mathrm{N} \quad$ Normal Mean & 35 \\
Parametersa,b Std. Deviation & 0000000 \\
Most Extreme Absolute & 6,64224640 \\
Differences Positive & 110 \\
Negative & 110 \\
Test Statistic & -087 \\
Asymp. Sig. (2-tailed) & 110 \\
& $200^{c, d}$ \\
\hline
\end{tabular}

a. Test distribution is Normal.

Sumber : Pengolahan data dengan SPSS 23
Berdasarkan tabel diatas, diperoleh nilai Asymp. Sig. (2-tailed) sebesar 0,200 . Nilai tersebut lebih besar dari taraf signifikan 0,05, maka dapat disimpulkan bahwa data berdistribusi normal.

\section{b. Uji Linieritas}

Uji Linieritas bertujuan untuk mengetahui apakah antar variabel terikat (Y) dan variabel bebas (X) mempunyi hubungan linier

Tabel 6. Hasil Uji Linieritas

ANOVA $^{a}$

\begin{tabular}{|l|r|r|r|r|r|}
\hline Model & $\begin{array}{r}\text { Sum of } \\
\text { Squares }\end{array}$ & df & $\begin{array}{r}\text { Mean } \\
\text { Square }\end{array}$ & $F$ & Sig. \\
\hline 1 Regression & 674,225 & 1 & 674,225 & 14,832 &, 001 \\
Residual & 1500,061 & 33 & 45,456 & & \\
Total & 2174,286 & 34 & & & \\
\hline
\end{tabular}

a. Dependent Variable: Hasil_belaj

b. Predictors: (Constant

Strategi_pembelajaran_everyone_is_a_teac her_here

Sumber : Pengolahan data dengan SPSS 23

\section{c. Uji Regeresi Linier Sederhana}

Metode regresi linier sederhana ini dimaksudkan untuk mengetahui seberapa besar tingkat pengaruh antara variabel Independen (X) dan Variabel Dependen (Y). 
Volume 3. No.2 Agustus 2020 (96-107)

Doi 10.30596/liabilities.v3i2.5592

Tabel 7. Uji Regresi Linier Sederhana Coefficients $^{\mathrm{a}}$

\begin{tabular}{|c|c|c|c|c|c|}
\hline \multirow[b]{2}{*}{ Model } & \multicolumn{2}{|c|}{$\begin{array}{l}\text { Unstandardized } \\
\text { Coefficients }\end{array}$} & \multirow{2}{*}{$\begin{array}{c}\begin{array}{c}\text { Stand } \\
\text { ardize } \\
d \\
\text { Coeffic } \\
\text { ients }\end{array} \\
\text { Beta }\end{array}$} & \multirow[b]{2}{*}{$t$} & \multirow[b]{2}{*}{ Sig } \\
\hline & B & $\begin{array}{l}\text { Std. } \\
\text { Error }\end{array}$ & & & \\
\hline $\begin{array}{c}1 \text { (Consta } \\
n t)\end{array}$ & 64,177 & 5,562 & & 11,538 & ,000 \\
\hline $\begin{array}{l}\text { Strategi } \\
\text { pembela } \\
\text { jaran } \\
\text { everyon } \\
\text { e is a } \\
\text { teacher } \\
\text { here }\end{array}$ & 265 & ,069 & 557, & 3,851 & ,001 \\
\hline
\end{tabular}

a. Dependent Variable: Hasil_belajar

Dari tabel diatas terlihat bahwa nilai $h$ sebesar 14,832 . Untuk $\mathrm{n}-2=35-2$ $=33$ dengan $\mathrm{df}=1$ terlihat bahwa $h$ $>14,832>$ 4,14 maka H0 ditolak jadi erdapat hubngan linier antara variabel $\mathrm{X}$ dengan variabel $\mathrm{Y}$

Persamaan regersi sederhana yang digunakan adalah:

$$
\mathbf{Y}=\mathbf{a}+\mathbf{b X}
$$

$$
Y=64,177+0,265 X
$$

Berdasarkan persamaan regresi linier diatas diketahui nilai konstantanya sebesar 64,177. secara matematis, nilai konstanta ini menyatakan bahwa tanpa dilaksanakan strategi pembelajaran Everyone is a Teacher Here, maka hasil belajar siswa memiliki nilai
64,177. Selanjutnya nilai positif $(0,265)$ adalah koefisien regresi variabel $\mathrm{X}$ (Strategi Pembelajaran Everyone Is a Teacher Here) menggambarkan bahwa arah hubungan antara variabel X (Strategi Pembelajaran Everyone Is a Teacher Here) dengan variabel Y (Hasil belajar siswa) adalah searah, dimana setiap kenaikan satu satuan variabel $\mathrm{X}$ (Strategi Pembelajaran Everyone Is a Teacher Here) akan menyebabkan kenaikan hasil belajar siswa 0,265.

\section{d. Uji Korelasi}

Analisis korelasi digunakan untuk mengetahui kekuatan hubungan antara korelasi anatara kedua variabel dimana variabel lainnya dianggap berpengaruh dikendalikan atau dibuat tetap (sebagai variabel control).

\begin{tabular}{|c|c|c|c|}
\hline & & $X$ & $Y$ \\
\hline \multirow[t]{2}{*}{$X$} & $\begin{array}{l}\text { Pearson Correlation } \\
\text { Sig. (2-tailed) }\end{array}$ & 1 & $\begin{array}{c}, 557^{* *} \\
001\end{array}$ \\
\hline & $\mathrm{N}$ & 35 & 35 \\
\hline \multirow[t]{2}{*}{$Y$} & $\begin{array}{l}\text { Pearson Correlation } \\
\text { Sig. (2-tailed) }\end{array}$ & $\begin{array}{l}, 557^{* *} \\
, 001\end{array}$ & 1 \\
\hline & $\mathrm{N}$ & 35 & 35 \\
\hline
\end{tabular}

Tabel 8. Uji Korelasi

Dari tabel diatas terlihat bahwa dari segi nilai sig(2-tailed) anatara Strategi Everyone is a teacher here (X) 
dengan Hasil belajar (Y) adalah sebesar $0,001<0,05$ yang berarti terdapat korelasi yang signifikan antara variabel $\mathrm{X}$ dengan variabel $\mathrm{Y}$. Berdasarkan nilai $r$ hitung untuk hubungan Strategi Everyone is a teacher here $(\mathrm{X})$ dengan Hasil belajar (X) adalah sebesar 0,557, sedangkan $r$ tabel df $=35-2=33$ dengan taraf signifikan 0,05 adalah 0,333 jadi $r$ hitung $>\mathrm{r}$ tabel yaitu $0,557>0,333$ maka ada hubungan atau korelasi antara strategi pembelajaran everyone is a teacher here dengan hasil belajar.

\section{e. Uji Koefisien Determinan}

Untuk mengetahui dan mengukur seberapa besar pengaruh Strategi Pembelajaran Everyone Is a Teacher here $(\mathrm{X})$ terhadap hasil belajar $(\mathrm{Y})$ dengan ketentuan nilai koefisien determinasi adalah 0 dan 1 .

\section{Tabel 9. Uji Koefisien Determinan}

\begin{tabular}{|c|c|c|c|c|}
\multicolumn{2}{|c|}{ ' Model Summary } \\
\hline \multirow{2}{*}{ Model } & $\mathrm{R}$ & $\begin{array}{c}\mathrm{R} \\
\text { Square }\end{array}$ & $\begin{array}{c}\text { Adjusted } \\
\text { R Square }\end{array}$ & $\begin{array}{c}\text { Std. Error of } \\
\text { the Estimate }\end{array}$ \\
\hline 1 &, $557^{\mathrm{a}}$ &, 310 &, 289 & 6,742 \\
\hline
\end{tabular}

a. Predictors: (Constant), X

Dari tabel diatas terlihat bahwa hasil belajar siswa dipengaruhi oleh Strategi pembelajaran Everyone Is a Teacher Here dengan tingkat presentase $31,00 \%(0,310 \times 100 \%)$ dan sisanya $69,00 \%$ ( $100 \%$ $31,00 \%$ ) ditentukan oleh variabel yang lain yang tidak diteliti (diluar dari variavel penelitian).

\section{f. Uji Hipotesis}

Uji Hipotesis digunakan untuk menguji hipotesis apakah kebenaranya diterima atau ditolak. Pengujian hipotesis penelitian, dilakukan dengan menggunakan uji-t.

\section{Tabel 10. Uji t}

\begin{tabular}{|c|c|c|c|c|c|}
\hline \multirow[b]{2}{*}{ Model } & \multicolumn{2}{|c|}{$\begin{array}{c}\text { Unstandardiz } \\
\text { ed } \\
\text { Coefficients }\end{array}$} & \multirow{2}{*}{$\begin{array}{c}\begin{array}{c}\text { Standardi } \\
\text { zed } \\
\text { Coefficient } \\
\mathrm{s}\end{array} \\
\text { Beta }\end{array}$} & \multirow[b]{2}{*}{$\mathrm{t}$} & \multirow[b]{2}{*}{ Sig. } \\
\hline & B & $\begin{array}{l}\text { Std. } \\
\text { Error }\end{array}$ & & & \\
\hline (Constant) & $\begin{array}{r}64,1 \\
77\end{array}$ & 5,562 & & $\begin{array}{r}11,5 \\
38\end{array}$ & ,000 \\
\hline $\begin{array}{l}\text { Strategi } \\
\text { pembelaj } \\
\text { aran } \\
\text { everyone } \\
\text { is a } \\
\text { teacher } \\
\text { here }\end{array}$ & ,265 & ,069 & ,557 & $\begin{array}{r}3,85 \\
1\end{array}$ & ,001 \\
\hline
\end{tabular}

a. Dependent Variable: Hasil_belajar Sumber : Pengolahan data menggunakan SPSS

Dari tabel diatas terlihat bahwa variabel $\mathrm{X}$ (Strategi pembelajaran Everyone Is a Teacher Here (X) memperoleh thitung sebesar 3,851 dengan signifikan 0,001 dan nilai tabel pada taraf signifikan $\alpha=0,05$ dengan $(\mathrm{df})=\mathrm{N}-2=35-2=33$ diperoleh sebesar 1,692 maka thitung 3,851 > tabel 
1,692 dengan taraf signifikan $5 \%$. Berdasarkan Kriteria pengujian hipotesis Jika thitung > ttabel maka Ho di tolak Ha di terima sedangkan Jika thitung $<$ ttabel maka Ho di terima Ha di tolak, dengan demikian pada penelitian ini hipotesis diterima. Ini dapat disimpulkan bahwa ada pengaruh yang signifikan antara strategi pembelajaran everyone is a teacher here terhadap hasil belajar.

\section{PEMBAHASAN}

Penelitian ini dilaksanakan dengan tujuan untuk mengetahui apakah strategi pembelajaran everyone is a teacher here berpengaruh terhadap hasil belajar siswa akuntansi kelas XI AK-1 SMK PAB 2 Helvetia Tahun Pelajaran 219/2020. Sebelum penilitian dilakukan terlebih dahulu peneliti melakukan pengujian terhadap angket, berupa uji validitas dan uji reliabilitas. Adapun uji coba ini dilakukan di kelas XI AK-1 SMK Ar-rahman medan dengan jumlah siswa 40 orang. Setelah dilakukan uji validitas angket yang digunakan sebagai instrument penelitian dari 20 butir angket yang diuji ternyata 20 butir angket yang valid. Dari hasil penelitian mengungkapkan bahwa terdapat pengaruh yang signifikan penggunaan Strategi Everyone is a teacher here terhadap hasil belajar akuntansi. Hipotesis ini memiliki hubungan yang berarti dan signifikan pada taraf signifikasi $=0,05$. Sesuai dengan hasil penelitian diperoleh hasil uji hipotesis $h=8,296$ dan $=$ 1,692 maka $h>$ sehingga dapat dikatakan ada pengaruh penggunaan strategi pembelajaran everyone is a teacher here terhadap hasil belajar siswa akuntansi.

\section{KESIMPULAN}

1. Hasil penilitian yang dilakukan dikelas XI AK-1 PAB 2 Helvetia Tahun pelajaran 2019/2020, diketahui bahwa rata-rata hasil belajar siswa adalah sebesar $92,00 \%$

2. Persamaan regresi linier sederhana yaitu $Y=64,177+0,265 X$. Dari persamaan regresi linier sederhana tersebut nilai bahwa nilai a (angka kontan) dari Unstandardized Coefficient adalah 64,177. Hal ini berarti bahwa jika tidak ada strategi everyone is a teacher here (X) maka nilai hasil belajar (Y) adalah sebesar 64,177. Sedangkan b (angka koefisien regresi) 
nilainya sebesar 0,265 , hal ini menunjukkan bahwa setiap penambahan $1 \%$ tingkat strategi pembelajaran everyone is a teachere here (X) maka hasil belajar (Y) akan meningkat sebesar 0,265. Karena nilai koefisien regresi bernilai positif dengan demikian dapat dikatakan bahwa strategi everyone is a teachere here $(\mathrm{X})$ berpengaruh positif terhadap hasil belajar (Y).

3. Dari perhitungan uji hipotesis (uji t) diketahui nilai $\mathrm{t}$ adalah sebesar 3,851. Berdasarkan tabel, dengan derajat kebebasan $(\mathrm{df})=35-2=33$, dengan $\mathrm{a}=5 \%$, maka tabel $=1,692$ karena thitung $>$ tabel $(3,851>1,692)$ dapat disimpulkan ada pengaruh yang signifikan antara strategi pembelajaran everyone is a teachere here terhadap hasil belajar akuntansi.

4. Pengujian determinasi menghasilkan besarnya pengaruh strategi pembelajaran everyone is a teacher here terhadap hasil belajar siswa akuntansi kelas XI AK-1 SMK PAB 2 Helvetia Tahun Pelajaran 2019/2020 sebesar $31,00 \% \quad(0,310 \quad x \quad 100 \%)$ dan sisanya $69,00 \%(100 \%-31,00 \%)$ ditentukan oleh variabel yang lain yang tidak diteliti (diluar dari variabel penelitian).

\section{SARAN}

1. Siswa harus dituntut berani mengungkapkan pendapatnya di depan teman-temannya untuk melatih siswa dalam berani berbicara didepan umum.

2. Dalam kegiatan pembelajaran, guru hendaknya menggunakan strategi pembelajaran yang tepat dan berfokus pada siswa sehingga materi dapat tersampaikan dengan sebaik-baiknya.

3. Bagi guru bidang studi akuntansi agar lebih kreatif dan menerapkan strategi everyone is a teacher here untuk dapat meningkatkan hasil belajar akuntansi siswa dalam kegiatan pembelajaran serta didampingi dengan media lainnya.

4. Bagi peniliti selanjutnya diharapkan agar mengkaji lebih dalam mengenai materi dan referensi dalam melakukan penelitian serta lebih memperhatikan dan merencanakan alokasi waktu dengan tepat karna strategi everyone is a teacher here 
Volume 3. No.2 Agustus 2020 (96-107)

Doi 10.30596/liabilities.v3i2.5592

membutuhkan waktu yang cukup

lama selama proses pembelajaran.

\section{Daftar Pustaka}

Darmansya 2012. Strategi Pembelajara Menyenangkan Dengan Humor. Jakarta PT.Bumi Aksara

Harti, Dwi. 2018. Akuntansi Keuangan. Jakarta: Erlangga

Pratama, A.S, dan Muslim, S. 2013. Pengaruh Model Pembelajaran Kooperatif Tipe Every One is a Teacher Here terhadap Hasil Belajar Siswa pada Standar Kompetensi menafsirkan Gambar Teknik Listrik di SMK Negeri 2 Surabaya. Jurnal Pendidikan teknik Electro. Vol 2 (2):861-868

Purwanto. 2011. Evaluasi Hasil Belajar. Yogyakarta:Pustaka Belajar

Rasyidin, Al dan Nur Wahyuddin.2012. Teori Belajar dan Pembelajaran. Medan: Perdana Publishing

Rusman.2015. Pembelajaran Tematik Terpadu: Teori, Praktik dan Penilaian Jakarta: Rajawali Pers

Sabri, Ahmad. 2005. Metode Belajar Mengajar. Jakarta:

Quantum Teaching

Siregar, Syofian. 2014. Statistik Parametrik untuk Penelitian
Kuantitatif. Jakarta: Bumi Aksara

Suprijono, A. 2013. Cooperative Learning. Yogyakarta: Pustaka Pelajar

Suprihatiningrum, Jamil. 2017. Strategi Pembelajaran. Yogyakarta: Ar-Ruzz Media

Sugiono. 2012. Metode Penelitian Pendidikan. $\quad$ Bandung: Alfabeta

2017. Statistika untuk Penelitian. Bandung: Alfabeta

Warsono. 2017. Pembelajaran Aktif. Bandung: Remaja Rosdakarya

Zaini, Bermawy dan Sekar Ayu Aryani. 2017. Strategi Pembelajaran Aktif. Yogyakarta: Pustaka Insan Madani 